\title{
A atuação da Organização dos Estados Americanos (OEA) e de sua burocracia internacional na defesa da democracia no continente americano ${ }^{1}$
}

\author{
Jan Marcel de Almeida Freitas Lacerda \\ Professor Doutor da Universidade Federal do \\ Tocantins, Porto Nacional, Tocantins, Brasil \\ janmarcell@gmail.com \\ Jeane Silva de Freitas \\ Doutoranda pela Universidade Federal de \\ Pernambuco, Recife, Pernambuco, Brasil \\ jeanesfreitas@hotmail.com
}

Resumo Este artigo apresenta a Organização dos Estados Americanos (OEA) e sua burocracia internacional em uma das suas áreas temáticas de atuação no continente americano: a defesa da democracia. Assim, para estudo de caso, aborda-se a atuação da Organização e de sua burocracia na proteção e promoção da democracia no continente americano, principalmente nas crises mais recentes em Honduras (2009) e no Paraguai (2012). Em primeiro lugar, objetiva-se compreender e descrever a OEA e sua burocracia, mas também detalhar o surgimento do sistema interamericano, principalmente na defesa da democracia como tipo ideal de governo para os países da região e constituindo uma burocracia da OEA para atuar nessa área temática, a Secretaria de Fortalecimento da Democracia (SFD). Em seguida, analisa-se os casos de transgressão do sistema interamericano de defesa da democracia em Honduras, em 2009, e no Paraguai, em 2012, destacando a centralidade da influência do Secretário-Geral da organização na resolução de crises políticas.

Palavras-chave: OEA, burocracia internacional, construtivismo, democracia, continente americano.

1 É importante mencionar que este artigo é um resultado de pesquisas mais aprofundadas de um dos autores (Lacerda, 2011; Lacerda, 2013a; Lacerda, 2013b; Lacerda, 2015; Lacerda, 2017). 


\section{Introdução}

O presente artigo busca compreender a forma como a Organização dos Estados Americanos (OEA) e sua burocracia internacional influencia nas relações internacionais do continente americano, especialmente observando a atuação do secretariado, das agências, dos programas, das secretarias e dos servidores civis internacionais. Sobretudo, restringese a pesquisa à influência da Organização na promoção e na defesa da democracia como modelo ideal de governo para os Estados membros.

Segundo Barnett e Finnemore (2004, p. vii), a burocracia é uma forma social distinta de organização social, com sua própria lógica interna e que gera suas tendências comportamentais particulares. A existência de hierarquia, continuidade, impessoalidade e conhecimento adquirido ou especializado ${ }^{2}$ são quatro características que qualificam uma Organização Internacional (OI) como uma burocracia moderna, eficiente e como ator diferenciado dos seus Estados membros.

Biermann e Siebenhüner (2009, p. 6-7) definem as burocracias internacionais como agências que tem uma configuração constituída por governos e outros atores públicos, com algum grau de permanência e coerência e independente de um controle formal de um governo particular e que agem na seara internacional em busca de uma política. As burocracias são partes das Organizações Internacionais e, para os autores, evidencia-se um conceito menos amplo que se comparado ao conceito de Barnett e Finnemore (2004), já que esses últimos utilizam os termos como sinônimos, ou seja, as OI são entendidas como burocracias internacionais. É uma evolução da literatura sobre burocracias internacionais e é a compreensão teórica utilizada pelo presente artigo.

Opta-se por uma abordagem construtivista ou constitutiva ${ }^{3}$ da OEA, já que se observam os processos de constituição de significados compartilhados e estruturas

2 “As burocracias modernas apresentam hierarquia, em que cada funcionário tem uma esfera de competência claramente definida dentro de uma divisão do trabalho e é responsável perante seus superiores; continuidade, em que o escritório constitui uma estrutura de salários a tempo completo, que oferece a perspectiva de avanço regular de carreira; impessoalidade, em que o trabalho é realizado de acordo com as regras prescritas e procedimentos operacionais que eliminem influências arbitrárias e politizadas; e conhecimento adquirido ou especializado, em que os funcionários são selecionados para conhecimento armazenado em arquivos (Barnett; Finnemore, 2004, p 17-18, grifo do autor, tradução livre)".

3 Conforme Fearon e Wendt (2002, p. 84-85), a abordagem constitutiva se pergunta sobre as condições sociais de possibilidade dos atores em um determinado momento, buscando explicar do que os atores são feitos, ou como suas estruturas são formadas ou possivelmente seu impacto na sociedade em que estão inseridas. 
intersubjetivas, ${ }^{4}$ como é o caso dos conceitos e estruturas em defesa da democracia no continente americano. Assim como observado por Beck (2008), esta pesquisa abarca as duas grandes preocupações da perspectiva construtivista, que são o contexto social e a relevância dos atores não estatais. Vale ressaltar que é indiscutível a importância dos Estados como atores no contexto internacional, mas o foco deste estudo é a influência exercida pelas burocracias internacionais.

Busca-se aqui responder o seguinte problema de pesquisa: de que forma a OEA e sua burocracia internacional atuam na defesa da democracia no continente americano? Para tanto, parte-se da hipótese de que a OEA e sua burocracia internacional impactam na construção de realidades internacionais e de estruturas burocráticas no continente americano, especialmente como autoridade na promoção e proteção da democracia como forma ideal de governo para seus Estados membros.

O método dedutivo é o adotado pela pesquisa, pois parte das concepções gerais dos estudos de Organizações Internacionais e de Burocracias Internacionais, para especificar nas concepções particulares da influência da OEA e de sua burocracia na área temática de normativas acerca da democracia no continente americano. Quanto aos métodos de procedimento ou auxiliares, haverá a utilização dos seguintes métodos: histórico, que permitirá analisar acerca da evolução da democracia na OEA; e estudo de caso, já que se busca aplicar os apontamentos teóricos sobre a atuação da organização regional e de sua burocracia nos casos de transgressão da democracia em Honduras (2009) e no Paraguai (2012). A pesquisa é, em geral, qualitativa e fundamenta-se em revisões literárias, análise de documentos e de discursos.

A partir dos apontamentos conceituais e teóricos sobre burocracias internacionais e dos apontamentos metodológicos acima, este artigo foca na constituição da organização e, em destaque, na temática da defesa da democracia, analisando as ações e funções do Secretariado Geral e da Secretaria de Fortalecimento da Democracia (SFD) da OEA. Em seguida, são abordados os dois estudos de caso da atuação da organização estudada no âmbito político-democrático dos Estados: as crises políticas das democracias de Honduras, em 2009, e do Paraguai, em 2012.

\section{A OEA, sua construção como ator internacional e a defesa da democracia}

A OEA é uma organização internacional estabelecida em 1948, através de sua carta constitutiva. Conforme o artigo $1^{\circ}$, da Carta da OEA, o intuito da organização é o de conseguir manter uma ordem de paz e justiça, promover a solidariedade, intensificar

4 Diferentemente de uma realidade objetiva e externa, como preceituam os teóricos racionalistas das Relações Internacionais, para os autores construtivistas há: “[...] uma realidade intersubjetiva, isto é: afirmam que entre agentes humanos, inclusive entre os que atuam em nome dos Estados, é possível haver entendimento mútuo, idéias comuns, práticas conjuntas e regras comuns que adquirem uma posição social independentemente de qualquer destes agentes. Coletivamente, essas regras e práticas constituem uma realidade política intersubjetiva” (Jackson; Sørense, 2007, p. 347-348). 
a colaboração e defender a soberania, a integridade territorial e a independência do continente americano (OEA, 1948). A organização é composta por 35 Estados membros do hemisfério americano e o sistema interamericano é caracterizado por ser uma rede de disposições e instituições, tendo por objetivos mais importantes e princípios basilares: a democracia, os direitos humanos, a segurança e o desenvolvimento (OEA, 2017a).

Com o fim da Guerra Fria, a cooperação interamericana progrediu consideravelmente e cresceu o interesse em renovar a organização. As mudanças e continuidades na esfera internacional representaram a definição de uma agenda mais abrangente, incorporando novos temas, novos atores, aumento dos fluxos de informações e uma configuração de vários níveis da governança global. As organizações regionais foram destacadas como complementares às organizações internacionais globais, gerando novos desenhos institucionais e atividades (Herz, 2011, p. 17-20).

A organização regional é um fórum central para a criação de normas regionais de proteção de regimes e instituições democráticas, estando envolvidas em gestão de crises políticas e de desenvolvimento institucional dos Estados americanos. Um conjunto de práticas foi ampliado, com destaque às assistências eleitorais, aos debates, às atividades educativas e à promoção de informações sobre governança democrática. Logo, a democracia passou a ser um dos principais objetivos da OEA (Herz, 2011, p. 59-64). Consoante Herz e Hoffmann (2004, p. 26, tradução nossa): "a OEA é frequentemente retratada como um fórum onde altas políticas são resolvidas, assim é relevante ressaltar que a organização lida com uma série de questões técnicas e sociais cruciais para os esforços de desenvolvimento nas Américas".

A OEA não só cria e institucionaliza as normas, mas também cria instrumentos jurídicos para a aplicação eficaz de suas normas, com a capacitação dos principais atores implicados em processos desse tipo.A organização é o mais alto nível político e técnico (ou ainda jurídico), com um conjunto de instâncias e uma Carta constitutiva (Arrighi, 2004, p. 91). Adiciona Arrighi (2004, p. 92): "Estes mecanismos podem ser órgãos específicos, instituídos expressamente, ou meios mais flexíveis, como a apresentação periódica de relatórios por parte dos Estados e sua avaliação por instâncias técnicas ou políticas". Assim, para este estudo, a autoridade conhecedora (expertise) da OI e de seus mecanismos é uma característica de autoridade, evidenciando suas burocracias especializadas nas mais diversas temáticas e ampliando suas funções constituídas pelos Estados. É o caso da atuação do Secretariado Geral e da Secretaria de Assuntos Políticos (SAP) na defesa da democracia no continente americano.

Para Cooper e Legler (2006), há construção no direito à democracia e a um paradigma de defesa coletiva de democracia na OEA, entendido pelos autores como um movimento em direção a uma doutrina de solidariedade democrática. Essa construção foi acelerada com o fim da Guerra Fria e com a onda de democratização que atingiu os países do continente americano. Perina (2001, p. 1) visualiza que há o papel da OEA na construção 
de um Regime Democrático Interamericano (REDI), ${ }^{5}$ que se caracteriza pela defesa da democracia e da economia de livre mercado.

O interesse pela democracia no sistema interamericano tem larga trajetória histórica e surgiu desde as primeiras conferências interamericanas (Perina, 2001). O conceito de democracia institucionalizado desde a sua criação com a Carta da OEA, de 1948, foi o conceito de democracia representativa, conforme o artigo $5^{\circ}$, alínea $\mathrm{d}$, da carta constitutiva original: "d) A solidariedade dos Estados Americanos e os altos fins que ela visa requerem a organização política dos mesmos com base no exercício efetivo da democracia representativa" (OEA, 1948, não paginado). Desse modo, representa a institucionalização na burocracia OEA como um dos princípios da organização e evidencia-se como âmbito de solidariedade entre os Estados membros para a defesa do ideal de organização político democrática.

Princípios da democracia foram se materializando na organização e se desenvolveram em certos instrumentos jurídicos e/ou diplomáticos, como, em particular: (1) o Protocolo de Cartagena, em 1985; (2) a Resolução 1080, de 1991, da Assembleia Geral da OEA; (3) o Protocolo de Washington de 1992; e (4) a Carta Democrática Interamericana, em 2001 (OEA, 1985; OEA, 1991; OEA, 1992; OEA, 2001). O primeiro instrumento constituiu-se nas mudanças introduzidas na Carta da OEA, em 1985, tendo o Protocolo de Cartagena das Índias aumentado as obrigações da organização para avançar o respeito à democracia, ao explicar que é um dos propósitos essenciais da organização promover e consolidar a democracia, com respeito ao princípio da não intervenção ${ }^{6}$ (Cooper; Legler, 2006, p. 25).

As mudanças também deram maior poder para o Secretário Geral da OEA, através do artigo 110, no qual o Secretário poderá chamar a atenção da Assembleia Geral e do Conselho Permanente em qualquer caso que em sua opinião reflita preocupação substancial acerca da ruptura da paz, a segurança e o desenvolvimento de um Estado membro (OEA, 1985).

O segundo instrumento da OEA é a Resolução nº 1080 da Assembleia Geral, adotada na vigésima quinta sessão em Santiago, Chile, em junho de 1991, com denominação "Democracia Representativa" (OEA, 1991; Perina, 2001). Essa declaração teve sua importância para o sistema, pois as reformas na Carta em 1985 não especificavam o tipo de ação que a organização deveria tomar no objetivo de promover e consolidar a democracia representativa - artigo $2^{\circ}$, alínea b, da Carta da OEA (Cooper; Legler, 2006). Com isso, a Resolução n 1080 tinha o efeito de reiterar o compromisso dos Estados

5 Há consonância com o conceito de $\operatorname{Krasner~(1982,~p.~1),~já~que~um~regime~internacional~é~"um~}$ conjunto de princípios, normas, regras e procedimentos decisórios em torno dos quais as expectativas dos atores convergem em uma área temática".

6 Esse propósito foi emendado pelo protocolo através da alínea b, do artigo 2, no Capítulo 1 Natureza e Propósitos - da Carta da OEA. Na íntegra:"Artigo 2. Para realizar os princípios em que se baseia e para cumprir com suas obrigações regionais, de acordo com a Carta das Nações Unidas, a Organização dos Estados Americanos estabelece como propósitos essenciais os seguintes: a) Garantir a paz e a segurança continentais; b) Promover e consolidar a democracia representativa, respeitado o princípio da nâo-intervençâo; [...] (OEA, 1985). 
membros da organização, contudo, a partir dessa resolução, de atuar de forma coletiva e imediata para proteger a democracia ameaçada (Perina, 2001).

Novamente, o Secretário-Geral ganha novas atribuições, pois, caso haja evento de interrupção de um governo democrático na região, a Resolução $n^{\circ} 1080$ instrui que o Secretário-Geral deve imediatamente convocar a reunião do Conselho Permanente e promover uma reunião ad hoc dos Ministros das Relações Exteriores e/ou uma sessão especial da Assembleia Geral (OEA, 1991). Conforme Cooper e Legler (2006), esses primeiros instrumentos adicionaram alguns elementos para a emergência de uma doutrina pró-democrática, bem como teve três fatores positivos: primeiro, contribuiu para um procedimento novo e automático; segundo, a Resolução deu licença a OEA para utilizar um ranque de atividades coletivas da instituição para resolver uma crise democrática; e terceiro, enfatizou o princípio da rápida resposta (10 dias para tomar decisões).

O terceiro instrumento foi o Protocolo de Washington de 1992, aprovado como reforma da Carta da OEA e teve sua vigência apenas em 1997, adicionando o artigo 9, que contempla o tratamento de suspensão do Estado membro e/ou excluir das atividades da Organização um governo que não surja de um processo democrático ou que seja instituído através da força. O referido protocolo adicionou um novo aspecto para a doutrina democrática, a democracia representativa como um critério de participação na burocracia OEA (OEA, 1992; Perina, 2001; Cooper; Legler, 2006).

A OEA também criou um mecanismo instrucional para ajudar na disseminação da democracia na região, que foi a Unidade para a Promoção da Democracia (UPD) (Cooper; Legler, 2006). A UPD foi instituída pela Resolução n ${ }^{\circ} 1063$ da Assembleia Geral e, posteriormente, refinada pela Resolução n ${ }^{\circ} 572$ do Conselho Permanente, tendo mandato:"inclui construção institucional democrática, geração de informação, divulgação e intercâmbio sobre a democracia, promoção do diálogo democrático entre especialistas e instituições do hemisfério, e observação e assistência técnica" (Cooper; Legler, 2006, p. 26, tradução nossa).

A UPD foi renomeada como Departamento para a Promoção da Democracia (DPD) e a importância particular desse departamento seria o trabalho em monitoramento externo de eleições. Para Perina (2001), diferentemente do caráter dissuasivo e reativo, de imediato, da Resolução no 1080 , as atividades da UPD apontavam para ações democráticas de médio ou longo prazo, com o intuito de fortalecimento da institucionalidade democrática e trabalho preventivo. Torna-se um importante mecanismo da OEA na promoção, fortalecimento e consolidação de valores e práticas democráticas, mas não são papéis exclusivos desse departamento.

Herz (2008, p. 20) destaca que o DPD se concentrou na área de observações eleitorais, em particular denominadas de Missões de Observação Eleitoral (MOE) da OEA. ${ }^{7}$ Como autoridades nas mais diversas áreas de atuação, as OI são frequentemente solicitadas para

7 Essas missões foram institucionalizadas inicialmente a partir do mandato da "Resolución sobre derechos humanos, democracia y observación electoral (1989)", mesmo verificando-se que houve a realização de observações desde a década de 1960 (OEA, 2008, p. 12). 
resolverem problemas. Desse modo, por meio de seu poder racional-legal, tendem a construir soluções racional-legais e favorecer suas autoridades racional-legais (Barnett; Finnemore, 2004 p. 34). Essa é a lógica das Missões de Observação Eleitoral da OEA, pois a organização observa e ajuda o processo eleitoral dos países solicitantes. Segundo Barnett e Finnemore (Barnett; Finnemore, 2004, p. 34, tradução nossa): "Soluções que envolvem regulamento, arbitragem e intervenção de uma autoridade racional-legal (elas próprias ou de outras organizações) parecem sensatas, racionais e boas para as OI e, assim, desproporcionalmente emergem da atividade da OI".

Esta pesquisa visualizou que o DPD novamente mudou de denominação e suas atribuições estão inseridas na Secretaria de Assuntos Políticos (SAP) da OEA, que é uma secretaria de apoio ao Secretário-Geral.Em 2015, mudou para Secretaria de Fortalecimento da Democracia (SFD) (OEA, 2015). Divide-se em três departamentos: Departamento de Cooperação e Observação Eleitoral (DCOE); Departamento de Sustentabilidade Democrática e Missões Especiais (DSDME); e Departamento de Gestão Pública Efetiva (DGPE). Há também um Escritório Executivo do Secretário de Fortalecimento da Democracia (OEA, 2017b).

O quarto instrumento de defesa democracia na OEA é a Carta Democrática Interamericana (CDI), que passou a cumprir a função de principal instrumento da OEA no aqui reforçado regime democrático interamericano. Essa carta democrática foi importante também nas missões de observação referidas acima, pois consagrou o caráter instrumental das missões de observação eleitoral no hemisfério, em particular está estabelecido explicitamente no Capítulo V da CDI - "A democracia e as missões de observação eleitoral”. Isto posto, todas as concepções sobre as missões eleitorais da organização foram institucionalizadas e disseminadas pela CDI (OEA, 2001; OEA, 2008).

Outros elementos da CDI são importantes para este estudo. Primeiro, a democracia é vista como um direito e essencial para o desenvolvimento social, político e econômico (artigo $1^{\circ}$ ), ou seja, o termo "direito" implica uma obrigação e dá força à democracia, assim como há a interligação da ideia de democracia além da área e responsabilidades políticas. Segundo, o artigo $2^{\circ}$ exterioriza o conceito adotado pela OEA como o de democracia representativa e que a participação do cidadão é apenas um aspecto inserido nesse tipo de democracia. Terceiro, os artigos $3^{\circ}$ e $4^{\circ}$ abarcam elementos essenciais para a caracterização de um governo como democrático e ainda como critérios necessários para a consolidação da democracia (OEA, 2001).

Quarto, o capítuloV - A democracia e os Direitos Humanos - pontua principalmente que a democracia é indispensável para o exercício efetivo dos direitos humanos. Quinto, o capítulo IV da CDI - Fortalecimento e preservação da institucionalidade democrática - traz os agentes, os procedimentos e as sanções para os países em que há ruptura da ordem democrática, em particular destaque-se o artigo 19, que estabelece a cláusula democrática da OEA.E, por último, o capítuloVI - Promoção da cultura democrática -, trazendo valores e práticas democráticas para a consolidação de uma cultura democrática 
no hemisfério, em particular aqui se sobressalta os programas de educação da infância e da juventude (artigo 27) (OEA, 2001).

É importante ressaltar que, segundo Arrighi (2009), a aprovação da CDI através de uma resolução da Assembleia Geral é tida, por este artigo, como uma forma de ganho institucional da OEA e nova interpretação de uma fonte diferente de direito internacional e legalização das relações internacionais no continente americano. Preferiu-se adotar a Carta Democrática como resolução, já que, se fosse um tratado de reforma da Carta da OEA, precisaria de ratificação dos Estados. Com isso, por meio de respaldo do Comitê Jurídico Interamericano, decidiu-se por adotar a forma de resolução, abrangendo seus efeitos para todos os Estados membros da organização, diferentemente de um tratado que só obriga os seus ratificantes (Arrighi, 2009).

Mesmo que a Carta tenha sido aprovada por consenso, não é percebida como uma fonte clara de obrigação jurídica coercitiva para os Estados (Capponi;Tapia, 2012), ou seja, é uma normativa que tem grande força política e complexa obrigação jurídica. Cooper e Legler (2006) ressalvam que os elementos e condições para democracia constituídos nos artigos 3, 4, 5 e 6 da CDI não são consenso na organização OEA, visto que:

no contexto da democracia representativa, não há sistema político ou método eleitoral que seja igualmente adequado para todas as nações e seus povos e os esforços da comunidade internacional para reforçar a eficácia do princípio de que a realização de eleições genuínas e episódicas não deva pôr em dúvida o direito soberano de cada Estado de eleger e desenvolver seus sistemas políticos, sociais e culturais livremente, se eles são ou não para a conexão de outros Estados (Cooper; Legler, 2006, p. 29, tradução nossa).

Em outras palavras, ficou claro que não havia consenso em adotar uma fórmula universal de democracia representativa, mas esse conceito configurou-se como o denominador comum entre os Estados do continente americano. É importante relevar que, como observado pelo Manual de Observações Eleitorais da OEA (2008), há declarações, resoluções e recomendações das mais diversas sobre a democracia no hemisfério e ainda não só sobre a democracia representativa, mas também mencionando a democracia participativa. Então, visualiza-se que, apesar do predomínio da concepção de democracia representativa na OEA, há outras concepções em debate.

$\mathrm{Na}$ obra da OEA em homenagem ao aniversário da CDI, o conceito de "democracia republicana" foi mencionado pelo seu Secretário-Geral, do seguinte modo:

Ao definir quais são os elementos essenciais da democracia representativa e os componentes fundamentais do exercício democrático, a Carta Democrática Interamericana pode ser concebida como um "programa da República Democrática". Como qualquer programa político, inclui um ideal a ser alcançado e estabelece a direção para a qual os Estados Membros devem dirigir seus esforços. Este paradigma da democracia republicana, por sua vez, é fundamental para definir as linhas programáticas que tanto a Organização como cada um dos Estados Membros poderia usar como um guia para priorizar e selecionar as iniciativas, projetos e ações a serem realizadas no 
interesse da consolidação e fortalecimento da democracia. (Insulza, 2011, p. 3 , tradução nossa).

Assim, observa-se que o conceito de democracia para o posto de liderança dos servidores civis internacionais é diferente da ideia acordada pelos Estados da OEA, os quais advogam a democracia representativa como forma de regime político dos Estados membros da organização regional. No entanto, há claramente a defesa de ganhos em prol do bem público e tornar-se uma posição "meio-termo" entre as esferas dos Estados e dos servidores, o que evidencia a qualidade típica de mediação que geralmente é adotada por Secretários-Gerais de Organizações Internacionais.

Nessa seara, de acordo com Cooper e Legler (2006), há a importância também da internalização de uma cultura democrática na própria organização e que o SecretárioGeral da OEA durante os anos de 1994 e 2004, César Gaviria, teve um papel central nesse processo, haja vista que:

intelectualmente, Gaviria assumiu a liderança na promoção de um "paradigma da solidariedade democrática" interamericana. Burocraticamente, Gaviria injetou algum sangue novo na organização. Em vez de aceitar a noção de que a OEA era a preservação da geração mais velha, Gaviria cercou-se de um "jardim de infância" de talentosos assessores mais jovens. Operacionalmente, ele estava disposto a dobrar a restrição de uso do multilateralismo de clube visà-vis a de seus "bons ofícios" para defender e promover a democracia através de várias ações, incluindo a emissão de declarações à imprensa frequentes em situações de preocupação na região, de missões de investigação para pontos problemáticos, e mediação de terceiros, ou melhor facilitação como a OEA veio denominá-la (Cooper; Legler, 2006, p. 17, tradução nossa).

Conforme o trecho acima, pode-se visualizar novamente a importância do SecretárioGeral na promoção da defesa da democracia, bem como da equipe da organização.

Portanto, como analisado ao longo deste tópico sobre a burocracia OEA, há nessa organização uma construção evolutiva de normativas em promoção e defesa da democracia representativa. Assim, observa Villa (2003) que o quadro de referência normativo da instituição OEA, os seus instrumentos operacionais e suas missões de observação eleitoral possuem enfoques na defesa do aspecto eleitoral da democracia, evidenciando o seu conceito institucionalizado de democracia representativa. Entretanto, recorrentes críticas e crises ao sistema de defesa da democracia da OEA vêm ocorrendo no continente americano e aqui se destaca neste artigo a crise em Honduras (2009) e no Paraguai (2012) e as subsequentes respostas e ações da organização.

\section{A OEA e as crises políticas}

Conforme Barnett e Finnemore (2004), a autoridade está intrinsecamente ligada à credibilidade das OI. Consequentemente, a OEA vem perdendo sua credibilidade atualmente na defesa e promoção da democracia, ao passo que não conseguiu resolver, de 
forma rápida e satisfatória para a comunidade internacional, as crises políticas de ruptura da ordem democrática em Honduras (2009) e no Paraguai (2012).

A OEA lida com limitações quanto à intervenção nos Estados, ou seja, para regular e controlar efetivamente o comportamento dos Estados membros (Perina, 2001), já que há a limitação da organização na obrigatoriedade e cumprimento das obrigações constituídas na OEA. Em outras palavras, a organização regional depende da vontade, dos interesses, da capacidade persuasiva e coercitiva dos Estados em crise e/ou da comunidade internacional para a aplicação de suas disposições. Tanto as missões especiais de observação quanto a ajuda em crises políticas devem partir ou serem solicitadas pelo Estado em crise, e caso haja intervenção sem a concessão do Estado, como se verificou em Honduras, o âmbito de ação da organização fica bastante enfraquecido, pois os apoios dos determinantes domésticos são fundamentais para que haja a restauração e a sustentabilidade democrática.

Como posto pelo Secretário-Geral em discurso em 2009, a OEA tem força preventiva quanto às crises políticas, mas que ainda assim apresenta limitações, pois "é que não há clareza sobre quando ou sob quais condições há um grave colapso da democracia ou pode haver uma séria ruptura na democracia" (Insulza, 2009, não paginado).

Perina (2001) compreende que os instrumentos, ações e medidas políticodiplomáticas e jurídicas da OEA são elementos coletivos de curto prazo, nos quais se responde de forma automática e imediata às ameaças a democracia dos Estados Membros. Assim, a organização atua de duas formas: 1) quando alerta para possíveis transgressões são instrumentos protetivos ou dissuasivos; e 2) quando já há transgressão são instrumentos reativos ou corretivos, os quais permitem a ação coletiva para restaurar as condições de democracia. Portanto, busca-se aqui observar a atuação da OEA e de sua burocracia internacional nas crises políticas de Honduras, em 2009, e Paraguai, em 2011.

\section{Crise democrática em Honduras (2009)}

Em junho de 2009, um golpe de Estado ocorreu em Honduras contra o governo do presidente eleito José Manuel Zelaya, sendo ele arbitrariamente preso e levado à força para o exílio. O caso de Honduras levantou a fragilidade do poder reativo da OEA de restaurar a ordem democrática depois de sua violação, pois a organização estava chegando em Honduras com uma missão especial a pedido do presidente Zelaya, mas antes mesmo ocorreu o golpe (Insulza, 2009).

A crise política em Honduras foi consequência da deposição do então presidente, Manuel Zelaya, por um golpe militar de Estado, justificado pela suposta pretensão do presidente de mudar a Constituição do país e instituir a reeleição (Insulza, 2009). Em consequência, de acordo com mecanismos da CDI (2001), o Conselho Permanente da OEA condenou os acontecimentos no país e convocou uma sessão extraordinária da Assembleia Geral, que também condenou os fatos contra a ordem democrática em Honduras e exigiu o retorno do presidente Zelaya às suas funções (OEA, 2018).

Diante da recusa do regime político instituído com o golpe em cumprir as disposições da Assembleia, esse órgão decidiu, em 4 de julho, suspender o país do exercício de seu 
direito de participar da organização regional, em consonância com o artigo 21 da CDI (OEA, 2001). O órgão decisório da OEA também encarregou o Secretário-Geral para aprofundar iniciativas diplomáticas e a promover outras medidas para o restabelecimento da democracia no país. Com isso, várias iniciativas foram estabelecidas, como: o apoio às ações do então Presidente da Costa Rica, Óscar Arias; duas missões de chanceleres; a mediação do Diálogo de Guaymuras; e a assinatura do Acordo de Tegucigalpa, San José (OEA, 2018).

O então Secretário-Geral da OEA, Insulza, argumentou que todas as sanções possíveis foram aplicadas ao Estado Hondurenho, desde sanções econômicas e políticas à suspensão do Estado da organização, por meio da resolução AG/RES.1 (XXXVII-E/09), que versava sobre a crise política em Honduras e que decidiu pela exclusão do governo hondurenho de sua participação no sistema interamericano da OEA (OEA, 2009). Meses após o ocorrido, o Secretário-Geral, tendo em vista que as medidas não surtiram os efeitos esperados, decidiu que a OEA deveria voltar a apoiar Honduras, pois se acreditava que a forma de diálogo político e diplomático seria a melhor maneira de ajudar o país e "porque as sansiones econômicas não funcionam: a única coisa que elas fazem é prejudicar as pessoas que as sofrem diretamente e em Honduras já existe uma situação econômica dificil” (Insulza, 2009, não paginado).

Além disso, defendeu o Secretário-Geral, a necessidade de esclarecer as concepções de ruptura da ordem político democrática e a forma que a OEA agirá em tais circunstâncias, haja vista que:

Seria um avanço que deveríamos tentar alcançar na Carta Democrática Interamericana, definindo muito mais explicitamente quais são as rupturas, tomando conta delas e ampliando o acesso aos recursos multilaterais da OEA a todos os ramos do Estado que consideram que a Constituição do seu país está sendo violado. (Insulza, 2009, não paginado, tradução nossa).

Em junho de 2010, a Assembleia Geral da OEA instruiu o Secretário-Geral a formar uma Comissão de Alto Nível para avaliar a situação política no país. Em 29 de junho de 2010, a Comissão apresentou seu relatório e defendeu, em geral, que: 1) a necessidade de resolver a questão legal do ex-presidente Zelaya, permitindo o seu retorno a Honduras e o gozo de seus direitos; 2) ações práticas para cumprimento das recomendações feitas pela Comissão Interamericana de Direitos Humanos (CIDH); e 3) elogiou e reafirmou a importância da criação da Comissão daVerdade e Reconciliação por parte do governo de Honduras. Essa Comissão constituída pelo Secretário-Geral da OEA foi essencial para o delineamento do retorno do país à organização (OEA, 2018).

Em maio de 2011, outro passo importante para a reincorporação de Honduras foi a sentença da Suprema Corte de Honduras que anulou o processo contra o ex-presidente Zelaya e, em 11 de junho de 2011, em sessão especial da Assembleia Geral, a suspensão do país foi revogada (Artigo 22, da CDI) (OEA, 2001, 2018). A missão política de bons oficios da OEA em Honduras atuou de 2009 a 2011. 
Jan Marcel de Almeida Freitas Lacerda (UFT); Jeane Silva de Freitas (UFPE).

Em 2012, a OEA enviou uma Missão de Observação Eleitoral para acompanhar as eleições no país, especialmente com a postulação do cargo de presidente. A MOE/OEA parabenizou os esforços do Tribunal Superior Eleitoral na realização do pleito eleitoral, mas mostrou-se preocupada com os problemas de coberta e conectividade entre as várias regiões durante a transmissão dos resultados da eleição e o que gerou incerteza para vários atores inseridos no processo. A missão fez diversas recomendações ${ }^{8}$ ao país e suas instituições e, para este artigo, reafirmou a relevância da inserção da organização regional no restabelecimento das democracias no continente americano, com seus aparatos burocráticos de resolução de problemas racionais-legais, como é o caso também das missões de observação eleitoral para auxiliar os processos eleitorais dos países (OEA, 2012).

Assim sendo, destaca-se aqui a atuação do Secretário-Geral da OEA e das burocracias internacionais da organização, especialmente na configuração de bons ofícios, missões de facilitação e de observação eleitoral para agir na resolução das crises políticas e institucionais aos países em crise.

\section{Crise democrática no Paraguai (2012)}

Em 2012, o presidente eleito democraticamente Fernando Lugo Méndez foi destituído do governo do Paraguai em um processo de impeachment votada pelo Senado do país, aprofundando uma crise política e institucional que já vinha sendo desenhada no país desde os anos 2000. O processo de impeachment analisado no Senado paraguaio foi sob a acusação de desempenho negligente do presidente em um caso de violência contra camponeses, ocorrido em 15 de junho de 2012, em Curuguaty. Na ocasião, houve violência desproporcional no despejo de camponeses em terras disputadas, com a morte de 11 camponeses e 6 policiais. O processo jurídico ocorreu como previsto na constituição do país, mas sem a observância de requisitos processuais, como, por exemplo, o devido processo legal (UOL, 2012; OEA, 2018).

Nesse contexto, a OEA visualizou que o presidente paraguaio já vinha lidando com crises políticas desde a sua entrada no poder e, em consequência, sofreu, em 2012, um processo de impeachment em tempo curto e que feriu alguns preceitos legais de possibilidade de defesa, o que gerou desconforto na maioria dos Estados do continente, bem como de diversas das instituições e dos organismos internacionais (UOL, 2012; OEA, 2018).

Em consequência da crise democrática no Paraguai, os processos de integração regional MERCOSUL e UNASUL aplicaram suas cláusulas democráticas e suspenderam a participação do Estado paraguaio das instituições (Hoffmann, 2016). No entanto, a atitude da OEA foi diferenciada, pois, lidando com uma nova forma de golpe de Estado, já que o golpe se desenvolveu dentro da própria ordem constitucional do país, a organização regional se mostrou cautelosa quanto às sanções ao país e buscou compreender melhor a situação. www.oas.org/eomdatabase/MoeReport.aspx?Lang=es\&Id=239\&MissionId=300>. Acesso em: 15 abr. 2018. 
A OEA decidiu mandar missão especial do Secretário-Geral para o Paraguai, com o intuito de tomar notas sobre a realidade em crise. De acordo com Insulza (2012, não paginado): "é necessário lembrar que a maioria dos atores reconheceu a necessidade de promover reformas políticas que melhorem os procedimentos estipulados para julgamentos políticos, bem como outras medidas para fortalecer o sistema democrático". Consequentemente, o Secretário-Geral apontou três objetivos da OEA para a realidade no Paraguai: 1) chegar ao término do processo judicial contra o presidente, tanto nas instâncias paraguaias quanto em ordem jurídica da Comissão e Corte Interamericana de Direitos Humanos da OEA; 2) fortalecer a governabilidade do Paraguai até as eleições de 2013; e 3) assegurar um processo eleitoral participativo e transparente (Insulza, 2012).

Com isso, a OEA decidiu que, diferentemente da suspensão, como defendia alguns Estados e como feito por outras instituições da região, a organização regional preferiu aumentar a sua presença no Estado em crise e, assim, poder ajudar a sociedade e o sistema político paraguaio. Isto posto, Insulza defende que:

ao invés de promover sanções, devemos nos unir em torno de uma abordagem que privilegie o apoio da Organização para a realização de diálogos com uma visão de médio e longo prazo e que envolva os atores políticos paraguaios na superação da situação atua ao invés de promover sanções, devemos nos unir em torno de uma abordagem que privilegie o apoio da Organização para a realização de diálogos com uma visão de médio e longo prazo e que envolva os atores políticos paraguaios na superação da situação atua (Insulza, 2012, não paginado, tradução nossa).

Após receber o relatório do Secretário-Geral em 10 de julho de 2012, o Conselho Permanente recomendou o envio imediato de uma missão para acompanhar as eleições de abril de 2013, já que o processo de impeachment ocorreu acerca de dez meses antes das próximas eleições. A missão especial de acompanhamento político da OEA ao Paraguai foi aprovada e estabelecida, atuando durante o período de 2012 a 2013, com mandato para promover e consolidar a democracia representativa. Os funcionários da OEA visitaram o país mais de seis vezes e construíram um diálogo democrático com atores políticos e sociedade civil para debater questões fundamentais da política paraguaia (OEA, 2018).

Em 2013, a OEA enviou uma missão de observação eleitoral para o Paraguai e teve a eleição democrática do presidente Horacio Cartes, com cerca de $45 \%$ dos votos. A MOE/OEA agradeceu e reformou a importância da ação conjunta com a Justiça Eleitoral do país e fez profundas recomendações para melhorias do funcionamento do sistema eleitoral (OEA, 2013). ${ }^{9}$

Sendo assim, diferentemente das outras organizações regionais MERCOSUL E UNASUL, a OEA decidiu não aplicar a sua cláusula democrática (OEA, 2001) e isso aparentemente após aprender com a suspensão sem efeitos de Honduras em 2009. A

9 Para maiores informações sobre a MOE/OEA no Paraguai em 2013 e as recomendações feitais, acessar: <http://www.oas.org/EOMDatabase/MoeReport.aspx?Lang=es\&Id=165\&Mission $\mathrm{Id}=212>$. Acesso em: 18 abr. 2018. 
organização preferiu se inserir na crise política do país e ajudá-lo a restabelecer sua democracia. Sobretudo, há a relevância da atuação do Secretário-Geral da OEA e, através da MOE/OEA, da Secretaria de Fortalecimento Democrático.

\section{Considerações finais}

Por meio dos apontamentos teóricos constitutivos dos atores internacionais, objetivou-se compreender melhor a atuação das organizações internacionais e suas burocracias no meio internacional, especialmente da OEA na defesa da democracia para os Estados americanos. A escolha dos estudos de casos de Honduras (2009) e Paraguai (2012) se deu pelo interesse de analisar comparativamente a ação da organização na área temática objeto de estudo, buscando testar a hipótese de que a OEA e sua burocracia internacional impactam na construção de realidades internacionais e de estruturas burocráticas no continente americano, especialmente como autoridade na promoção e proteção da democracia como forma ideal de governo para seus Estados membros.

Optou-se por restringir a análise às normativas da OEA em defesa da democracia, partindo do entendimento de que a OEA não só cria instrumentos políticos e jurídicos como também capacita os principais atores implicados no processo (Arrighi, 2004). Observou-se a formação das normativas e estruturas burocráticas na área temática de estudo e suas concretizações institucionais, propagadoras e observadoras da realidade social inserida e constituída. É o caso da democracia e da criação do Regime Democrático Interamericano (REDI) (Perina, 2001) e, sobretudo, a atuação do Secretário-Geral e da Secretaria de Fortalecimento da Democracia.

Destaca-se o papel dos Secretários-Gerais da OEA nas decisões políticas e jurídicas quanto à defesa da democracia no continente americano, sendo a principal figura na avaliação e no acionamento do sistema interamericano para agir em crises políticas. A organização regional foi gradualmente adotando instrumentos jurídicos e diplomáticos (políticos) para estabelecer a democracia como forma de governo obrigatória para os seus Estados membros. O ápice desse processo foi a institucionalização da Carta Democrática Interamericana (CDI), em 2001 (Cooper; Legler, 2006).

Para os objetivos deste artigo, observou-se a criação da Secretaria de Fortalecimento da Democracia (SFD) da OEA, mas visualizou-se que é carente de força política e jurídica como mecanismo capaz de reação às transgressões da norma democrática. Apesar disso, a Secretaria mostrou uma relevante atuação burocrática na promoção e monitoramento da democracia no continente americano, principalmente agindo na prevenção contra crises político-democráticas e na configuração de missões de observação eleitoral. Reitera-se que este estudo também concorda acerca da importância dos Estados na defesa e promoção da democracia, mas foca-se na importância das organizações e burocracias internacionais.

Os casos das crises políticas ocorridas em Honduras, em 2009, e no Paraguai, em 2012, representaram episódios recentes de violação da normativa em defesa da democracia da 
OEA. Entretanto, as atitudes da OEA frente às crises políticas em Honduras e no Paraguai demonstraram as limitações da organização em restaurar a ordem democrática, como preceitua seus instrumentos políticos e jurídicos. Ou seja, conforme posto por Barnett e Finnemore (2004), a OEA pode perder autoridade quanto à defesa da democracia e também a sua credibilidade.

No caso de Honduras, a organização regional suspendeu a participação do país e aplicou sanções políticas e econômicas, contudo, o Secretário-Geral e a organização compreenderam que essas medidas não tiveram efeito e decidiram se reaproximar do país, com o intuito de ajudá-lo a restabelecer a sua ordem democrática (Insulza, 2009). Já no Paraguai, foi enviada uma missão especial do Secretário-Geral para avaliar a situação do país, sendo sugerido por ele que a organização não suspendesse a participação do país e ajudasse na crise política, principalmente averiguar e fortalecendo a condução das eleições que estavam próximas. O Secretário evidencia o aprendizado da burocracia no processo em Honduras (Insulza, 2012). Portanto, o papel do Secretário-Geral e da burocracia foi essencial para que se tomassem decisões políticas quanto às crises, não aplicando taxativamente o instrumento político e jurídico da CDI, a cláusula democrática.

Para este estudo, apesar das limitações da OEA, acredita-se que a burocracia da organização tem trabalhado em responder a essas demandas de crises políticas, mas conforme posto pelo próprio Secretário-Geral da OEA (2009, não paginado) sobre a crise de Honduras, há a necessidade de repensar os mecanismos e esclarecer as formas de utilização da Carta Democrática Interamericana (CDI). Isso requer a vontade dos Estados, ou seja, há a importância das opiniões e ideias dos burocratas da OEA, mas há também a exigibilidade da atitude dos Estados membros. Para Perina (2001), mesmo assim, há uma preocupação dos Estados com o poder da burocracia nas Organizações Internacionais, em especial quanto ao poder do Secretário-Geral, pois:

A eficácia e a eficácia de seu poder dependem da capacidade informal de liderança e formação de consenso de seu Secretário Geral, uma figura eleita pelos Estados membros a cada cinco anos. Os Estados membros sempre quiseram limitar os poderes da Secretaria Geral e são muito cuidadosos em ceder sua soberania a um poder supranacional. (Perina, 2001, p. 27).

Então, fica evidenciada a importância das burocracias da OEA na defesa da democracia, principalmente com a atuação do Secretário-Geral.A Secretaria de Assuntos Políticos (SAP) foi observada como tendo um papel subsidiário na aplicação dos instrumentos políticos e jurídicos, mas com ação importante no monitoramento das normas, na observação de eleições, na análise de crises políticas e no aporte ao Secretário-Geral e aos Estados membros sobre as realidades dos países em crise. Assim, a burocracia OEA em temática sobre a democracia age tanto com autoridade política quanto jurídica, mas com maior atuação da política em virtude das limitações jurídicas de suas normas nessa área-temática.

A OEA ainda carece de conceitos mais definidos de rupturas democráticas no continente e de mecanismos que, além do papel discricionário do Secretário-Geral, 
Jan Marcel de Almeida Freitas Lacerda (UFT); Jeane Silva de Freitas (UFPE)

possam agir com maior capacidade jurídica para dirimir sobre casos de problemáticos. Assim sendo, fica comprovada a hipótese deste trabalho de que, na seara de defesa da democracia, a OEA impacta na promoção e defesa da democracia no continente americano, principalmente através da ação de suas burocracias internacionais. Pondera-se aqui, então, que há um maior grau de atuação política do que jurídica, apesar de elementos de ambos.

\section{Referências}

ARRIGHI, Jean Miguel. El sistema interamericano y la defensa de la democracia. Agenda Internacional, Año XVI, n. 27, 2009, p. 69-94. Disponível em: <http://revistas.pucp.edu.pe/index.php/agendainternacional/article/ viewFile/3661/3640>. Acesso em: 20 jan. 2015.

OEA. Organização dos Estados Americanos. São Paulo: Manole, 2004.

BARNETT, Michael; FINNEMORE, Martha. Rules for the World: International Organizations in Global Politics. Ithaca, London: Cornell University Press, 2004.

BECK, Robert J. International law and international relations scholarship. In: ARMSTRONG, David (ed.). Routledge Handbook of International Law. London; New York; Routledge, Taylor \& Francis Group, 2008.

BENNER, Thorsten, MERGENTHALER, Stephamn; ROTMANN, Philipp. International bureaucracies: the contours of a (re)emerging research agenda. 2007. Disponível em: <http://citeseerx.ist.psu.edu/viewdoc/downl oad?doi $=10.1 \cdot 1 \cdot 614.2406 \&$ rep $=$ rep1\&type $=p d f>$. Acesso em: 07 nov. 2018.

BIERMANN, Frank et al. Studyind the influence of International Bureaucracies: A conceptual Framework. In: BIERMANN, Frank; SIEBENHÜNER, Bernd (ed.). Managers of global change: influence of international environmental bureaucracies. Cambridge, MA: MIT Press, 2009.

BIERMANN, Frank; SIEBENHÜNER, Bernd (ed.). Managers of global change: influence of international environmental bureaucracies. Cambridge, MA: MIT Press, 2009.

CAPPONI, María Fernanda Donoso; TAPIA, Rosario Valenzuela. Carta Democrática Interamericana: Origen y Análisis de su Aplicación. 2012. Disponível em: < http://repositorio.uchile.cl/bitstream/handle/2250/113624/ de-donoso_m.pdf?sequence=1\&isAllowed=y>. Acesso em: 07 nov. 2018.

COOPER, Andrew Fenton; LEGLER, Thomas. Intervention without intervening?: the

OAS defense and promotion of democracy in the Americas. 1. ed. New York, NY: Palgrave Macmillan, 2006.

FEARON, James; WENDT, Alexander. Rationalism v. Constructivism: A SkepticalView. In: CARLNAES, Walter; RISSE, Thomas; SIMMONS, Beth A. (ed.). Handbook of International Relations. London: SAGE Publications, 2002.

HERZ, Mônica. Does the Organisation of American States Matter? Crisis States Working Papers Series, n. 2, Working Paper 34, April 2008.

The Organization of American States (OAS): Global governance away from the media. Abingdon, Oxon; New York, NY: Routledge, 2011.

HERZ, Mônica; HOFFMANN, Andréa Ribeiro. Organizações Internacionais: História e Práticas. Rio de Janeiro: Elsevier, 2004.

INSULZA, José Miguel. Discursos del Secretario General: Desafios para la consolidación de la democracia en la región y el futuro de la integración hemisférica. 2009. Disponível em: $<$ http://www.oas.org/es/acerca/discurso_ secretario_general.asp?sCodigo $=09-0079>$. Acesso em: 12 nov. 2014.

Discursos del Secretario General: Informe de la misión del Secretario General de la OEA y delegación a la República del Paraguay. 2012. Disponível em: <http://www.oas.org/es/acerca/discurso_secretario_general. asp?sCodigo=12-0057>. Acesso em: 12 jan. 2013. 
La construcción de un legado en materia de promoción y protección de la democracia. In: OEA. Décimo aniversario de la Carta Democrática Interamericana: Un compromiso hemisférico con la democracia. 2011. Disponível em: <http://www.oas.org/docs/publications/Decimo\%20Aniversario\%20de\%20la\%20Carta\%20 Democratica\%20Interamericana.pdf>. Acesso em: 30 mar. 2013.

KRASNER, Stephen. Structural Causes and Regime Consequences:Regimes as InterveningVariables. International Organization, v. 36, n. 2, 1982. p. 185-205.

JACKSON, Robert; SØRENSEN, Georg. Introdução às Relações Internacionais: teorias e abordagens. Rio de Janeiro: Jorge Zahar, 2007.

LACERDA, Jan Marcel de Almeida Freitas. A contribuição da perspectiva construtivista para o estudo do PNUD $e$ da OEA na Democracia Latino-Americana. 2011. 56f. Trabalho Acadêmico Orientado (Graduação em Relações Internacionais) - Centro de Ciências Biológicas e Sociais Aplicadas, Departamento de Relações Internacionais. Universidade Estadual da Paraíba, João Pessoa, 2011.

A influência da ONU, da OEA, dos seus corpos burocráticos e de suas interações administrativas na promoção e na defesa da democracia na América Latina. 2017. 325f. Tese (Doutorado em Ciência Política) - Programa de PósGraduação em Ciência Política, Universidade Federal de Pernambuco, Recife, Pernambuco, 2017.

A Organização dos Estados Americanos (OEA) e a disseminação de ideias de democracia na América Latina. 2013. 190f. Dissertação (Mestrado em Relações Internacionais) - Universidade Estadual da Paraíba, Pró-Reitoria de Pós-Graduação e Pesquisa, João Pessoa, Paraíba, 2013a.

Burocracia e direito internacional: a Organização dos Estados Americanos (OEA) e a institucionalização, a disseminação e o monitoramento de normas de direitos humanos e de democracia. 81.f. 2015. Monografia (Graduação) - Centro de Ciências Jurídicas, Universidade Federal da Paraíba, João Pessoa, Paraíba, 2015.

O Papel das Ideias e das Organizações Internacionais nas Teorias das Relações Internacionais. Revista de Estudos Internacionais, v. 4, n. 1, p. 83-99, 2013b. Disponível em: <http://www.revistadeestudosinternacionais. com/uepb/index.php/rei/article/view/119/pdf>. Acesso em: 12 out. 2017.

OEA. AG/RES. 1080 (XXI-O/Ql). Democracia Representativa. 1991. Disponível em: <www.oas.org/xxxiiga/ portugues/documentos/democracia_repres.pdf>.Acesso em: 11 set. 2017.

AG/RES.1 (XXXVII-E/09). Resolução sobre a crise política em Honduras. 2009. Disponível em: <http://www.oas.org/consejo/pr/AG/resolucionesextraordinarias.asp>. Acesso em: 07 nov. 2018.

Carta da Organização dos Estados Americanos. 1948. Disponível em: <http://www.oas.org/dil/port/ tratados_A-41_Carta_da_Organiza\%C3\%A7\%C3\%A3o_dos_Estados_Americanos.htm>. Acesso em: 22 nov. 2014.

Carta Democrática Interamericana. 2001. Disponível em: <http://www.oas.org/OASpage/port/ Documents/Democractic_Charter.htm>.Acesso em: 03 nov. 2014.

CP/RES. 1055 (2036/15). Estructura de la Secretaría General. 2015. Disponível em: < http://www.oas. org/legal/spanish/gensec/cp34980s04.pdf>. Acesso em: 05 nov. 2017.

Honduras. Primarias 2012. 2012. Acesso em: <http://www.oas.org/EOMDatabase/moeInfo. aspx?Lang=es\&Id=239>. Acesso em: 18 abr. 2018.

. Manual para las Misiones de Observación Electoral de la Organización de los Estados Americanos. 2008. Disponível em: <https://www.oas.org/sap/docs/DECO/OAS\%20Manual\%20Spanish\%203-26.pdf>. Acesso em: 02 jan. 2015.

OAS Political Missions Map. 2018.Disponível em:<http://www.oas.org/sap/peacefund/PeaceMissions/ PoliticalMissionsMap.html>. Acesso em: 17 mar. 2018.

Paraguay. Elecciones Generales 2013. 2013. Acesso em: <http://www.oas.org/EOMDatabase/ MoeReport.aspx?Lang=es\&Id=165\&MissionId=212> . Acesso em: 18 abr. 2018.

Protocolo de Reforma da Carta da Organização dos Estados Americanos. 1985. Disponível em: <http://www. oas.org/juridico/portuguese/treaties/a-50.htm>. Acesso em: 20 jan. 2017. 
A atuação da Organização dos Estados Americanos (OEA) e de sua burocracia internacional na defesa da democracia no continente

Jan Marcel de Almeida Freitas Lacerda (UFT); Jeane Silva de Freitas (UFPE)

. Protocolo de Reformas a la Carta de la Organizacion de los Estados Americanos (A-56) "Protocolo de Washington". 1992. Disponível em: <https://www.oas.org/dil/esp/tratados_A-56_Protocolo_de_Washington.htm>. Acesso em: 1 set. 2017.

Quem somos. 2017a. Disponível em: <http://www.oas.org/pt/sobre/quem_somos.asp>.Acesso em: 17 mar. 2017a.

Secretaria de Assuntos Políticos. 2017b. Disponível em: <http://www.oas.org/es/sap/default.asp?exp=yes> Acesso em: 30 dez. 2017.

PERINA, R. M. El régimen democrático interamericano: El papel de la OEA. 2001. Disponível em: < http://www.oas. org/sap/publications/2001/art/art_002_01_spa.pdf>.Acesso em: 12 jan. 2015.

UOL. ENTENDA a crise que levou à destituição do presidente Lugo no Paraguai. Uol Notícias, São Paulo, 22 de jun. 2012. Disponível: <http://noticias.uol.com.br/internacional/ultimas-noticias/2012/06/22/entenda-acrise-que-levou-a-destituicao-do-presidente-lugo-no-paraguai.htm>. Acesso em: 10 jan. 2014.

VILLA, Rafael Duarte. A questão democrática na agenda da OEA no pós-Guerra Fria. Revista de Sociologia e Política, n. 20, p. 55-68, jun. 2003. 


\title{
The role of the Organization of American States (OAS) and its international bureaucracy in defense of democracy in the Americas
}

\begin{abstract}
This article presents the Organization of American States (OAS) and its international bureaucracy in one of its thematic areas of focus in the Americas: the defense of democracy. So, for case study, this article deals with the role of the Organization and its bureaucracy in the protection and promotion of democracy in the Americas, mainly in the most recent crises in Honduras (2009) and in Paraguay (2012). First, the objective is to understand and describe the OAS and its bureaucracy, but also detail the emergence of Inter-American system, mainly the defense of democracy as an ideal form of government for the countries of the region and constituting an OAS bureaucracy to act in this thematic area, the Secretariat for Strengthening Democracy (SSD). Then, we analyze the cases of breach of the inter-American system for the defense of democracy in Honduras in 2009, and Paraguay in 2012, highlighting the centrality of the organization's Secretary-General's influence in resolving political crises.
\end{abstract}

Keywords: OAS, international bureaucracy, constructivism, democracy, American continent.

\section{La actuación de la Organización de Estados Americanos (OEA) y de su burocracia internacional en la defensa de la democracia en el continente americano}

\section{Resumen}

Este artículo presenta a la Organización de Estados Americanos (OEA) y su burocracia internacional en una de sus áreas temáticas de actuación en el continente americano: la defensa de la democracia. Así, para estudio de caso, se aborda la actuación de la Organización y de su burocracia en la protección y promoción de la democracia en el continente americano, principalmente en las crisis más recientes en Honduras (2009) y en Paraguay (2012). En primer lugar, se pretende comprender y describir la OEA y su burocracia, pero también detallar el surgimiento del sistema interamericano, principalmente en la defensa de la democracia como tipo ideal de gobierno para los países de la región y constituyendo una burocracia de la OEA para actuar en esa área temática, la Secretaría de Fortalecimiento de la Democracia (SFD). A continuación, se analizan los casos de transgresión del sistema interamericano de defensa de la democracia en Honduras, en 2009, y en Paraguay, en 2012, destacando la centralidad de la influencia del Secretario General de la organización en la resolución de crisis políticas.

Palabras clave: OEA, burocracia internacional, constructivismo, democracia, continente americano. 